Published October 7

\title{
OPEN
ACCESS
}

\section{Impact of salmon farming on Atlantic cod spatio-temporal reproductive dynamics}

\author{
J. E. Skjæraasen ${ }^{1, *}$, Ø. Karlsen ${ }^{1}$, Ø. Langangen ${ }^{2}$, T. van der Meeren ${ }^{3}$, N. B. Keeley ${ }^{4}$, \\ M. S. Myksvoll ${ }^{1}$, G. Dahle ${ }^{1}$, E. Moland ${ }^{5}$, R. Nilsen ${ }^{4}$, K. M. Elvik Schrøder ${ }^{4}$, \\ R. J. Bannister ${ }^{1}$, E. M. Olsen ${ }^{5,6}$ \\ ${ }^{1}$ Institute of Marine Research, PO Box 1870, Nordnes, 5817 Bergen, Norway \\ ${ }^{2}$ Department of Biosciences, University of Oslo, PO Box 1066, Blindern, 0316 Oslo, Norway \\ ${ }^{3}$ Institute of Marine Research, Austevoll Research Station, Sauganeset 16, 5392 Storebø, Norway \\ ${ }^{4}$ Institute of Marine Research, Fram Centre, PO Box 6606, Langnes, 9296 Tromsø, Norway \\ ${ }^{5}$ Institute of Marine Research, Flødevigen, 4817 His, Norway \\ ${ }^{6}$ Centre for Coastal Research (CCR), Department of Natural Sciences, University of Agder, PO Box 422, 4604 Kristiansand, \\ Norway
}

\begin{abstract}
Salmon farming in marine net pens is a major activity in many temperate regions. This industry may affect coastal ecosystems in several ways, such as with waste pollution and parasite spillover. Less is known about the extent to which salmon farming disrupts the use of inshore spawning grounds by wild fish, such as the Atlantic cod Gadus morhua. Acoustic telemetry was therefore used to explore cod space use during the spawning season in a coastal region in midNorway with multiple salmon farms. Acoustic receivers were placed in clusters at 5 known cod spawning grounds and 6 nearby salmon farms. Data from 481 adult cod caught at the spawning grounds during 2017-2019 and equipped with acoustic telemetry transmitters were analysed. Overall, fewer fish were detected at farms than spawning grounds, even when accounting for distance from release point. Individual cod residency (days detected / duration of spawning period) was generally higher at the spawning grounds close to farms but low at the farms themselves, with little apparent spawning at the farm localities. In contrast, spawning was clearly occurring at the nearby spawning grounds, with cod spending weeks $(n=316)$ or months $(n=158)$ there during the spawning period. Males had longer residence times at spawning grounds than females, likely linked to the cod mating system. Overall, we found little support for the assertion that salmon farms disrupt inshore spawning dynamics of cod using nearby spawning grounds presently, either by attracting spawners to farms or causing fish to leave these grounds.
\end{abstract}

KEY WORDS: Environmental impacts · Gadus morhua · Finfish · Acoustic telemetry

\section{INTRODUCTION}

Atlantic salmon Salmo salar aquaculture is a booming industry in the North Atlantic region. Typically, salmon aquaculture occurs in coastal habitats such as fjords and inlets where fish are kept in large netpens and fed pelleted feed until they have reached commercial size for harvest. In Norway, more than

*Corresponding author: jones@hi.no
1000 locations are approved for aquaculture production, with between 500 and 700 farms active at any given time due to fallowing. A growing body of evidence indicates that such farms may have a considerable ecological impact on local ecosystems (Buschmann et al. 2006, Edwards 2015, Keeley et al. 2019); the high concentrations of salmon within farms may lead to rapid growth of salmonid parasites such as

(C) The authors 2021. Open Access under Creative Commons by Attribution Licence. Use, distribution and reproduction are unrestricted. Authors and original publication must be credited. 
sea lice which may be transferred to wild salmonids (Krkosek et al. 2007, Torrissen et al. 2013), faecal matter and pellet waste may enter the food web (Dempster et al. 2009, 2011), benthic community structure and sediment biogeochemical functioning might be altered (Brooks et al. 2003, Valdemarsen et al. 2012, Keeley et al. 2017, Woodcock et al. 2018) and, particularly pertinent to the present study, farms may attract large fish assemblages (Dempster et al. 2002, 2009, Uglem et al. 2009). In the case of saithe Pollachius virens, the presence of salmon farms may have altered the species' life-history dynamics, leading to a fjord-population that spends its entire life within fjords, whereas before the arrival of salmon farms, saithe would leave the coast and migrate to offshore spawning areas (Ottera \& Skilbrei 2014). Clearly, there appears to be considerable scope for salmon farming to affect the spawning dynamics of wild heterospecific fish.

Another species found underneath salmon farms along the Norwegian coast is Atlantic cod Gadus morhua (Dempster et al. 2009, 2011), or perhaps most likely and more specifically, the Norwegian coastal cod (NCC) - the common name given to cod found along the Norwegian coast. Genetic studies generally point to differentiation along the Norwegian coastline (Barth et al. 2017, Dahle et al. 2018, Johansen et al. 2020), while conventional and acoustic tagging typically indicate limited movement and a high degree of residency (Espeland et al. 2008, Moland et al. 2013). Unlike the migratory and genetically distinct northeast Arctic cod (NEAC) (Nordeide et al. 2011, Berg et al. 2016), the NCC has dwindled in numbers since the early 1990s and is estimated to be close to or at an historical low (ICES 2020). Thus, there is considerable impetus for examining how salmon farming might impact local NCC populations.

It has been unequivocally demonstrated that both juvenile and adult cod may be found underneath aquaculture farms (Dempster et al. 2009, 2011), but how their presence may affect the reproductive output of adults is not clear. Studies on fitness proxies have generally not indicated any negative effect of farming (Dempster et al. 2011, Barrett et al. 2018). However, these studies have not targeted how salmon farms may alter the behaviour and movement of cod in relation to usage of traditional spawning grounds. Across their geographical range it has been shown that cod, especially amongst the less migratory populations, may return to the same spawning grounds yearly (Robichaud \& Rose 2001, Skjæraasen et al. 2011). Dean et al. (2014) found that not only did cod return to the same spawning ground each year but that the interannual difference in average location on the spawning ground of individual cod varied by less than $10 \mathrm{~m}$. Cod spawning grounds are typically found along underwater features such as slopes or underwater mounts (sensu Ames 2004) and, in many cases, areas where retention of eggs and early life-stages are high (Hutchings et al. 1993). In summary, cod spawning grounds are not randomly located, and their location may matter, at least to some extent, for the survival of the offspring through the early life stages.

To investigate the potential effects of salmon cage farming on NCC life history, the project 'Impacts of salmon farming on Atlantic cod spawning grounds' (ICOD) was established in 2015. This project employed a variety of approaches, one of which was acoustic telemetry techniques, the results of which are the focus of the present study. This approach was used to examine the spawning dynamics of NCC at 5 known spawning grounds in a fjord complex in a coastal region of Mid-Norway. Two of the spawning grounds were situated close to operational salmon farms, whereas 3 spawning grounds were further away from any farm locations (see Fig. 1). Fish were caught at each of these spawning grounds, tagged and released at their capture ground. We then examined fish movement, residence time and behaviour on these spawning grounds to assess the potential impacts of salmon farming on the spawning dynamics of cod on nearby spawning grounds.

\section{MATERIALS AND METHODS}

\subsection{Deployment of grid}

The telemetry grid used in the present study consisted of 30 Vemco VR2W receivers deployed in November 2016 (Figs. 1 \& S1, Table S1 in the Supplement at www.int-res.com/articles/suppl/q013p399_ supp.pdf). Based on prior conversations with fishermen and the results of concurrent egg surveys showing the presence of recently spawned cod-sized eggs, most receivers $(n=25)$ were placed at stations centred in 5 different clusters, including 2 in spawning grounds close $(<1 \mathrm{~km})$ to large salmon farms (Glasøysvaet [C1, Stns 15-18] and Lauvøysvaet [C2, Stns 19-25]) and 3 control clusters (Araneset [C3, Stns 1-5], Åkvika [C4, Stns 6-9] and Dromnessundet [C5, Stns 10-14]). The control clusters were deployed in spawning areas situated $>5 \mathrm{~km}$ away from any large salmon farms. Six receivers were also deployed at the farming locations closest to these focal clusters (Stns 28-33; Figs. 1 \& S1, Table S2). 


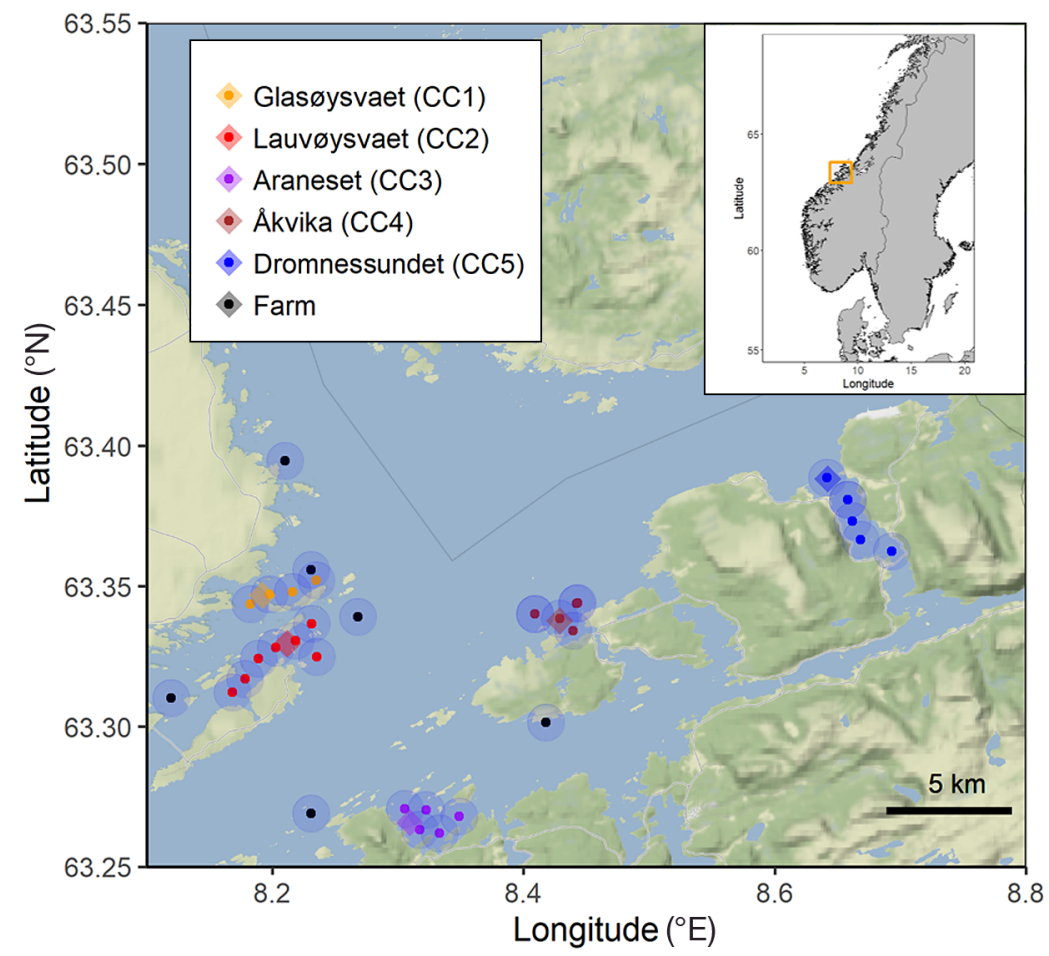

Fig. 1. Positions of the 30 stations providing data for the present study. Farm represents the location of salmon farms where a receiver was deployed. Insert in the top right corner shows the study area location, boxed, on the Norwegian coast. Transparent circles: approximate detection range of the receivers as calculated from range testing (i.e. outer circle edge represent approximate distance where $50 \%$ of tag transmissions are expected to be detected; see Text S1, Tables S3-S4, Figs. S2-S7 in the Supplement for further details). Diamonds: average release positions of fish post-tagging in each catch cluster; different stations are coloured according to the spawning ground they are monitoring

about 2 wk (Table S2). The yearly goal was to capture 40-60 fish from each cluster to ensure enough maturing males and females for tagging, although this was not always possible. Fishing was primarily done with the use of 2-chamber baited pots to minimize physical damage to the fish. These were typically deployed at 5-25 m depth to avoid barotrauma (Humborstad et al. 2017), with a maximal soak time of $48 \mathrm{~h}$. In 2018, catches in C3-C5 were augmented by hook and line fishing. Post-capture fish were transported to the tagging site at Vikan $\left(63.3804^{\circ} \mathrm{N}, 8.2011 \mathrm{E}^{\circ}\right)$ and placed in 5 individually marked net-pens ( $2 \mathrm{~m}$ diameter, $3 \mathrm{~m}$ deep, $9 \mathrm{~m}^{3}$ volume).

\subsection{Sampling and tagging procedure}

All fish were tagged in mid-February (Table S2). Cod were sedated using a mixture of benzocaine $(1.5 \mathrm{ml}$ per 101 seawater) and metomidate (5 $\mathrm{ml}$ per $10 \mathrm{l}$ seawater) and measured for total weight and length. Fish were tagged externally with T-bar tags (Hallprint), and 25-51 individuals from each cluster were also tagged with an

Four of the receivers deployed at the salmon farms were initially hung off central mooring locations at the farms. All remaining receivers were deployed on rigs anchored to the sea bottom by 2 iron chains with a total weight of $112 \mathrm{~kg}$. The receivers themselves were primarily placed at $\sim 10-12 \mathrm{~m}$ depth (Table S1) with the hydrophone facing down and, for rigs anchored to the bottom, with a sub-surface float at $\sim 8 \mathrm{~m}$ depth. From the sub-surface float to the surface, a secondary rope weighted down with chains was attached to a surface marker buoy fitted with a blinking marker light. Generally, all deployed receivers were kept at the same location (i.e. station) and recorded data for the duration of the study. Any exceptions are detailed in Table S1.

\subsection{Fish capture}

Fish capture was carried out in the same way in the 3 tagging years (2017-2019). Fishing would commence in late January/early February and last for internal acoustic transmitter every tagging year (see Table 2). The transmitter was inserted into the abdominal cavity through a $2-3 \mathrm{~cm}$ surgical incision made between the pelvic- and anal fin. The incision was then closed using absorbable sutures. Fish were also sexed, and their maturity stage was evaluated with the use of ultrasound (Karlsen \& Holm 1994). In 2018 and 2019, fish gender and female maturity stage were further ascertained by taking biopsy samples from all females (Witthames et al. 2009). After recovering in the net-pens for 1-2 d post-sampling, fish were released within their respective catch-clusters in the area where most catches had occurred (Fig. 1).

\subsection{Tag specifications}

In 2017 and 2019, fish were tagged with individually coded transmitters (Vemco V13P-1x-A69-9006; $\mathrm{n}_{2017}=194, \mathrm{n}_{2019}=189$ ). These transmitters operated on a frequency of $69 \mathrm{kHz}$ and were programmed to transmit a signal on average every 250 s (range: 
200-300 s). All tags were equipped with a pressure (depth) sensor operating down to $132 \mathrm{~m}$ and weighed $6.5 \mathrm{~g}$ in water ( $\square: 13 \mathrm{~mm}$, length: $48 \mathrm{~mm}$ ). Tags were programmed to turn off after 860 (2017) or 807 (2019) d to avoid problems with the separation of fish not being present and batteries being exhausted. In 2018 , fish were again tagged with individually coded transmitters (Vemco V13TP-1x-A69-9006; $\mathrm{n}=175$ ) with the same transmission specifications as in 2017 and 2019. However, these TP tags alternated between transmitting pressure $(\mathrm{P})$ or temperature $(\mathrm{T})$ in addition to Tag ID. The ratio between $\mathrm{T}$ and $\mathrm{P}$ transmissions was set to $1: 1$. Tags were programmed to turn off after $920 \mathrm{~d}$. In the present study, only Tag ID information was used.

\subsection{Data download and grid maintenance}

Generally, data was downloaded from all receivers twice yearly, and batteries changed in all receivers every $12 \mathrm{mo}$ (see Table S2). Additionally, the surface buoys with marker lights were checked and maintained approximately monthly. The detection range of the receivers deployed at the stations was estimated through range testing (Fig. 1), and the continued logging of detections and functioning of the grid was ascertained through the deployment of reference tags in each focal cluster and the examination of pings to detections ratios. For further details on these analyses see Text S1, Tables S2-S5, Figs. S2-S7.

\subsection{Data analyses}

To examine the potential impact of salmon farming on reproductive dynamics of cod on nearby grounds, we examined the occurrence of cod at the salmon farms during the spawning period and whether residence times indicated spawning activity was taking place underneath the farms, whilst comparing this to residence times at the different spawning grounds. Finally, we examined aspects of reproductive dynamics on each of the monitored spawning grounds, i.e. the residence index and linkage to other grounds, to evaluate if such metrics could be affected by farm proximity and to shed further light on the cod mating system in general.

All analyses, graphing and mapping were done using RStudio with R v.4.0.2 (R Core Team 2020). All graphing was done using 'ggplot2' (Wickham 2016), and mapping of the data was done using 'qqmap' (Kahle \& Wickham 2013). Organizing the data was done using the 'tidyverse' package (Wickham et al. 2019). Data analyses were conducted using the base library of $\mathrm{R}$ in addition to a variety of other packages when necessary. These latter packages are listed in the descriptions of the specific statistical analyses in which they were used. All model selection procedures followed the sample principle approach. An initial model was first employed, followed by use of the dredge command of the 'MuMIn' (Barton 2020) library or the sequential removal of non-significant terms to arrive at the most parsimonious model with the lowest value of Akaike's information criterion adjusted for small sample sizes (AICc). All variables that had been included in the best model or in a model with an AICc score less than 2 higher than the best model were retained for the final model used in the analyses, given that these models have been given similar empirical support (Hurvich \& Tsai 1989).

\subsubsection{Initial filtering and screening}

The data included in the present study covers the period from 15 February 2017 (the first release of fish) to 17 May 2020 (date of data download). Before conducting any analyses, the data of all individual fish were filtered based on logged depths, removing data where fish lacked vertical movement (other than that expected from tidal differences alone) for $>7 \mathrm{~d}$ (Villegas-Ríos et al. 2020). If the latter was found immediately post-release, all data for this individual were omitted, as it was deemed that the fish had not survived the tagging and release process. If this situation occurred after an initial period of vertical movement, only the data from the period of non-movement was omitted, as it was inferred that the fish had succumbed to natural or fishing mortality sometime after its release. This initial filtering left 9874590 detections in our database. A given transmission may also reach several loggers. A minimum off time of $200 \mathrm{~s}$ was programmed for each tag. To avoid inclusion of multi-detections, we filtered the data so that only the first logged detection was included if a transmission from the same fish with the same sensor value had been recorded on multiple loggers within $200 \mathrm{~s}$. To align receiver clocks, we used the time autocorrect function in the software Vue v.2.6.2 (Vemco) before exporting the data. This function uses a linear correction of the drift of the receivers' internal clock compared to the correct time, with the latter given by the time stamp from the computer satellite clock at the time of receiver initiation and data download. Finally, we screened the data for possible false detec- 
tions by omitting days where only a single detection was recorded for a given fish. This left 9159176 valid detections from 536 fish in the filtered data set. For the present study, we focussed on mature and sexed fish $(n=504)$ during the spawning period only. The spawning period was defined as the months of February to April, based on information gleaned from local fishermen, concurrent egg surveys (van der Meeren 2019) and examination of the female biopsy samples (authors' unpubl. data). This left us with a final data set containing 3579882 detections from 481 mature and sexed fish. For the mature and sexed fish not yielding data for the present study $(\mathrm{n}=$ 23), 10 were deemed to not have survived the tagging and release process and 13 were never detected.

\subsubsection{Number of cod at farms vs. spawning grounds}

We then tested if the amount of fish (FISH) recorded at farmed stations differed from that of nonfarmed sites (ST_TYPE), i.e. spawning grounds. We also took into account the possible effects of (1) distance (DIST) a given fish had to swim to get to the station where it was detected, i.e. the Euclidean distance from the release site to the detection station, (2) the number of fish released at the site yielding that particular distance (NREL) and (3) the number of years since release (YSR; release year given the value 1). Initial exploratory scatterplots indicated a non-linear response between distance and number of fish detected, and therefore we fitted a generalized additive model (GAM) to the data using the 'mgcv' library (Wood 2011):

$$
\begin{aligned}
& \mathrm{FISH}=\mathrm{s}(\mathrm{DIST})+\mathrm{NREL}+\mathrm{YSR}+\mathrm{ST} \_\mathrm{TYPE}+ \\
& \text { expyear }
\end{aligned}
$$

where expyear is the random effect of experimental year. DIST was smoothed in the GAM model, whereas the other terms were included as linear parametric effects. Numbers were further weighted by (1) the total number of detections to allow stations where fish had spent more time to have more weight in the analysis and (2) the inverse of the number of logging days for each station, given that the number of fish detected is expected to be positively associated with the number of logging days.

\subsubsection{Residence index during the spawning period}

Residence (a measure of fidelity) is commonly used in telemetry studies. Therefore, we calculated a resi- dence index (Res_Index) to examine the potential influence of farm proximity on this metric, defined here as the percentage of time a fish was detected during the pre-defined spawning period from 1 February to 30 April. This index was calculated by summing the number of days a fish had been detected and dividing this number by the total number of days of the spawning period. If experimental year equalled release year, the duration of the spawning period was adjusted by subtracting the number of days in February that had passed before fish release. Fish that were reported caught or inferred to have suffered natural mortality based on their depth profile during the spawning period were not included in these analyses. This index was calculated in 2 ways, using either (1) catch cluster (CCLUSTER) or (2) AREA as the grouping unit. AREA is a categorical variable with 6 levels (i.e. the 5 different spawning grounds and the farms). The difference between the 2 analyses is that for the latter, the residence index would be split between the spawning grounds or the farms if a fish was detected on multiple grounds. In the model, the categorical variable SEX was also included as an explanatory variable, and expyear was included as a random factor:

$$
\text { Res_Index }=\underset{\text { CCLUSTER } / A R E A}{\text { expyear }}+\text { SEX + }
$$

The test was followed by Tukey's post hoc tests for multiple group comparisons.

\subsubsection{Residence times on spawning grounds vs. farms}

To examine possible differences in spatiotemporal patterns at farm and spawning ground stations, residence time (Res_Time) was calculated using the VTrack library (Campbell et al. 2012). Res_Time was defined as the time from the first to the last detection of an individual cod at a given station, ending if (1) the cod was detected at another station or (2) there was a period of $>6 \mathrm{~h}$ without detections. At least 2 detections were required before a residence was assigned. Given that residence at a station ends if a fish is detected at another station and the distance to the neighbouring receiver generally is larger for the farmed stations, we calculated residence times for stations in 2 runs before pooling the results of the runs prior to analyses. Neighbouring stations were not included in the same run to prevent receiver spacing from influencing our results. The following initial linear mixed-effect model was then fitted to the data: 


$$
\begin{gathered}
\text { Res_Time }=\text { AREA + SEX + station } / \\
\text { serial + expyear }
\end{gathered}
$$

Serial (FishID) nested within station and expyear were the random effects included in the model. Residence time (in s) was log transformed in the analyses. The initial model run was followed by Tukey's post hoc test to compare the different areas.

We also wanted to investigate whether it was likely that spawning had taken place underneath the farms, or alternatively, somewhere within each spawning ground cluster. To examine if this was happening, we again calculated residence time using the same criteria as described above, but now considering all receivers in each spawning ground cluster as one unit. From these data, we selected the longest uninterrupted residence time each individual had recorded at (1) the spawning grounds and (2) the farms during the spawning period for each experimental year. Potential differences in the longest residence times between the different spawning grounds and the farms were tested with the model given in Eq. (4) followed by Tukey's post hoc tests:

$$
\text { Maximum_Res_Time }=\text { AREA }+ \text { SEX }
$$

\subsubsection{Origin of fish at the different spawning grounds}

Finally, we examined if there was a difference between spawning grounds in the likelihood of fish detected there not originating from that catch cluster. To determine this, we created the variable Migrant for all fish that had been detected at a spawning ground. Fish were given a value of 0 if they originated from the catch cluster released on the spawning ground in question and 1 if they originated from a different catch cluster. We then used a generalized linear model (GLM) to test if there was a difference between the spawning grounds in the likelihood of a detected fish being a migrant, where Migrant was treated as a binomial response variable and Spawning Ground as a categorical explanatory variable. Group-wise comparisons were done by a Tukey's post hoc test.

\section{RESULTS}

The average number, length and mass statistics for the 481 sexed mature cod Gadus morhua that yielded data for the study are given in Table 1. Sizes were similar between catch clusters, with the only consistent difference found being that fish in Lauvøysvaet were larger than fish at Araneset (Tukey's post hoc, p < 0.01). Females were consistently larger than males $(\mathrm{p}<0.0001$; Table 1$)$.

\subsection{Number of fish detected at spawning grounds vs. farms}

There was a distinct non-linear effect for the number of fish detected in relation to the distance fish had to swim to get to a station. Most fish had moved a relatively short distance, with the numbers quickly decreasing with distance and becoming more or less stable if a fish had to swim $>5 \mathrm{~km}(\mathrm{p}<0.0001$; Table 2, Fig. 2). The number of fish detected also increased with the number of fish released ( $p<0.0001$; Table 2$)$, and number of detected fish decreased with year since release ( $p<0.0001$; Table 2, Fig. 2). Given that spawning ground stations generally were closer to the release sites, the highest numbers of fish detected were at spawning ground stations (Fig. 2).

Table 1. Physical data for the acoustically tagged mature, sexed cod in the 5 different clusters (C1-C5) yielding data for the present study. Values are

\begin{tabular}{|c|c|c|c|c|c|c|}
\hline \multirow[t]{2}{*}{ Area (n) } & \multicolumn{3}{|c|}{ Females } & \multicolumn{3}{|c|}{ Males - } \\
\hline & Length (cm) & Weight (g) & $\mathrm{N}$ & Length (cm) & Weight (g) & $\mathrm{N}$ \\
\hline \multicolumn{7}{|l|}{2017} \\
\hline C1 (38) & $63.3( \pm 16.3)$ & $3267( \pm 2986)$ & 20 & $63.3( \pm 7.5)$ & $2839( \pm 1144)$ & 18 \\
\hline C2 (46) & $76.5( \pm 15.6)$ & $5779( \pm 3686)$ & 23 & $61.5( \pm 8.2)$ & $2647( \pm 1055)$ & 23 \\
\hline C3 (41) & $68.8( \pm 11.6)$ & $3601( \pm 2043)$ & 22 & $59.5( \pm 7.3)$ & $2242( \pm 863)$ & 19 \\
\hline C4 (30) & $73.4( \pm 12.7)$ & $4634( \pm 2239)$ & 14 & $61.3( \pm 10.1)$ & $2507( \pm 1057)$ & 16 \\
\hline C5 (34) & $65.7( \pm 13.5)$ & $3590( \pm 2564)$ & 19 & $58.3( \pm 6.9)$ & $2126( \pm 793)$ & 15 \\
\hline \multicolumn{7}{|l|}{2018} \\
\hline C1 (31) & $75.5( \pm 11.6)$ & $4827( \pm 2288)$ & 9 & $66.6( \pm 7.5)$ & $3338( \pm 1151)$ & 22 \\
\hline C2 (32) & $72.6( \pm 11.8)$ & $4503( \pm 2326)$ & 11 & $64.2( \pm 17.0)$ & $3345( \pm 3341)$ & 21 \\
\hline C3 (23) & $71.0( \pm 11.9)$ & $4278( \pm 2669)$ & 10 & $59.1( \pm 9.6)$ & $2334( \pm 1232)$ & 13 \\
\hline C4 (43) & $69.5( \pm 7.9)$ & $3860( \pm 1440)$ & 16 & $63.8( \pm 11.6)$ & $3175( \pm 2028)$ & 27 \\
\hline C5 (18) & $69.4( \pm 11.5)$ & $3921( \pm 2091)$ & 8 & $66.8( \pm 12.4)$ & $3658( \pm 2338)$ & 10 \\
\hline \multicolumn{7}{|l|}{2019} \\
\hline C1 (31) & $75.0( \pm 15.0)$ & $5191( \pm 3334)$ & 15 & $65.4( \pm 7.0)$ & $3182( \pm 1065)$ & 16 \\
\hline C2 (26) & $76.7( \pm 12.7)$ & $5254( \pm 2766)$ & 13 & $68.2( \pm 9.3)$ & $3501( \pm 1449)$ & 13 \\
\hline C3 (17) & $68.1( \pm 5.3)$ & $3167( \pm 752)$ & 11 & $60.0( \pm 6.5)$ & $2421( \pm 898)$ & 6 \\
\hline C4 (44) & $74.8( \pm 12.3)$ & $4909( \pm 2932)$ & 21 & $64.8( \pm 9.3)$ & $3149( \pm 2330)$ & 23 \\
\hline C5 (27) & $79.8( \pm 12.7)$ & $5838( \pm 3115)$ & 14 & $65.9( \pm 8.2)$ & $3224( \pm 1371)$ & 13 \\
\hline
\end{tabular}
average $( \pm \mathrm{SD})$ total length and weight for males and females and number (N) tagged 
Table 2. Determinants of the number of cod observed at a given station during the spawning period. Given predictors are the parametric explanatory variables Station Type (StType; categorical variable), number of fish released at a given distance from the station (NREL; continuous variable) and years since release (YSR; continuous variable). The treatment contrast of $\mathrm{R}$ was used with the intercept value representing the value for a spawning ground station. Square brackets indicate a categorical variable tested against the reference values. For these parametric explanatory variables, Estimate is the parameter estimate, $\mathrm{CI}$ is the $95 \%$ confidence interval and $\mathrm{p}$ is the $\mathrm{p}$-value for the predictors. For the smooth term, estimates is the estimated degrees of freedom (edf). Significance (bold) was assigned at $\mathrm{p}<0.05$. Only the fixed effects are shown

\begin{tabular}{|c|c|c|c|}
\hline \multirow{2}{*}{ Predictors } & \multirow[b]{2}{*}{ Estimates } & \multirow{2}{*}{$\begin{array}{r}\text { Fish } \\
\text { CI }\end{array}$} & \multirow[b]{2}{*}{$\mathrm{p}$} \\
\hline & & & \\
\hline Intercept & 16.22 & 12.27 to 20.17 & $<0.001$ \\
\hline StType [Farm] & -3.87 & -6.48 to -1.26 & 0.004 \\
\hline NREL & 0.41 & 0.32 to 0.50 & $<0.001$ \\
\hline YRS & -10.36 & -11.55 to -9.16 & $<0.001$ \\
\hline Smooth term (DIST) & & & $<0.001$ \\
\hline Observations & 579 & & \\
\hline $\mathrm{R}^{2}$ & 0.749 & & \\
\hline
\end{tabular}

However, when the distance from release site to the station of detection was taken into account, station type (i.e. farm or spawning ground), had a weak but significant negative effect on the numbers of fish detected ( $p<0.01$; Table 2, Fig. 2), with less fish detected at the farms.

\subsection{Residence index}

\subsubsection{Based on catch cluster}

Using catch cluster as the grouping variable, there were 563 residence indexes recorded involving 433 fish. The overall mean $( \pm \mathrm{SD})$ residence index was $0.45 \pm 0.36$, and the average number of days detected was $36 \pm$ $28.8 \mathrm{~d}$. Males had significantly longer residences than females (Table 3, Fig. 3). Fish from Lauvøysvaet overall had the highest indices, whereas Åkvika fish had the lowest (Table 3, Fig. 3). The Tukey post hoc test showed that the residence indices of fish from Lauvøysvaet was higher than all areas except the nearby Glasøysvaet. Fish from Glasøysvaet also had significantly higher residence indices than fish from Åkvika. No other differences were found (Table 3, Fig. 3).

\subsubsection{Based on area}

Using area as the grouping variable, there were 1032 residence indexes recorded involving 433 fish. The overall mean index value was $0.35 \pm 0.35$, and the average number of days detected was $26 \pm 27.5 \mathrm{~d}$ at the spawning grounds compared to an overall mean index of $0.096 \pm 0.16$ and an average number of detection days of $8.5 \pm 27.5 \mathrm{~d}$ at the farms. Once again, males had significantly longer residences than females (Table 3, Fig. 3). The Tukey post hoc test showed that residence indexes of fish at all spawning grounds were higher than at the farms (Table 3, Fig. 3). The residence indices recorded at Lauvøysvaet were also higher than fish from Glasøysvaet and Åkvika (Table 3, Fig. 3).

\subsection{Residence times}

A total of 28475 residence events were recorded for 479 fish at the different stations. There was no overall difference in residence time between any of the spawning grounds or the farms (Table S6, Fig. 4), but males had significantly longer residence times than females ( $p<0.001$; Table S6, Fig. 4). Notably, 
Table 3. Results of the cod residence index (Res Index) analyses using catch cluster (CC) or spawning grounds (SG) as the grouping variable. Square brackets indicate a categorical variable. The treatment contrast of $\mathrm{R}$ was used with the intercept representing the value for females at Glasøysvaet with values for the other CC/SG showing how they compare to this reference value. Letters show the results of Tukey's post hoc tests, with different letters indicating significant differences ( $p<0.05)$.

Significant p-values are shown in bold. Only fixed effects are shown

\begin{tabular}{|c|c|c|c|c|c|c|}
\hline \multirow[t]{2}{*}{ Predictors } & \multicolumn{3}{|c|}{- Res index-catch cluster } & \multirow[b]{2}{*}{ Estimates } & \multirow{2}{*}{$\begin{array}{c}\text { Res Index-area } \\
\text { CI }\end{array}$} & \multirow[b]{2}{*}{$\mathrm{p}$} \\
\hline & Estimates & $\mathrm{CI}$ & $\mathrm{p}$ & & & \\
\hline Intercept & $0.44^{\mathrm{a}}$ & 0.34 to 0.55 & $<0.001$ & $0.21^{\mathrm{a}}$ & 0.15 to 0.27 & $<0.001$ \\
\hline CC [Lauvøysvaet] & $0.13^{\mathrm{b}}$ & 0.05 to 0.22 & 0.002 & & & \\
\hline CC [Araneset] & $-0.12^{\mathrm{a}}$ & -0.21 to -0.02 & 0.013 & & & \\
\hline CC [Åkvika] & $-0.18^{\mathrm{c}}$ & -0.27 to -0.10 & $<0.001$ & & & \\
\hline CC [Dromnessundet] & $-0.08^{\mathrm{ac}}$ & -0.17 to 0.01 & 0.085 & & & \\
\hline $\operatorname{Sex}[\mathrm{M}]$ & 0.12 & 0.07 to 0.18 & $<0.001$ & 0.09 & 0.05 to 0.12 & $<0.001$ \\
\hline SG [Lauvøysvaet] & & & & $0.17^{\mathrm{b}}$ & 0.11 to 0.23 & $<0.001$ \\
\hline SG [Araneset] & & & & $0.08^{\mathrm{ab}}$ & 0.01 to 0.15 & 0.036 \\
\hline $\mathrm{SG}[\AA ̊ \mathrm{kvika}]$ & & & & $-0.02^{\mathrm{a}}$ & -0.08 to 0.04 & 0.506 \\
\hline SG [Dromnessundet] & & & & $0.09^{\mathrm{ab}}$ & 0.01 to 0.16 & 0.020 \\
\hline [Farm] & & & & $-0.16^{\mathrm{c}}$ & -0.22 to -0.10 & $<0.001$ \\
\hline Observations & & 571 & & & 1032 & \\
\hline Marginal $\mathrm{R}^{2}$ / Conditional $\mathrm{R}^{2}$ & & $0.132 / 0.176$ & & & $0.144 / 0.159$ & \\
\hline
\end{tabular}

the included fixed effects explained less than $4 \%$ of the total variation in residence times (Table S6), and there was considerable variation between stations within the different spawning grounds (Fig. 4).

Considering only the longest residence time of each fish yearly and using the spawning grounds as our unit, there was a significant difference between the spawning grounds and the farms (Fig. 5). Once

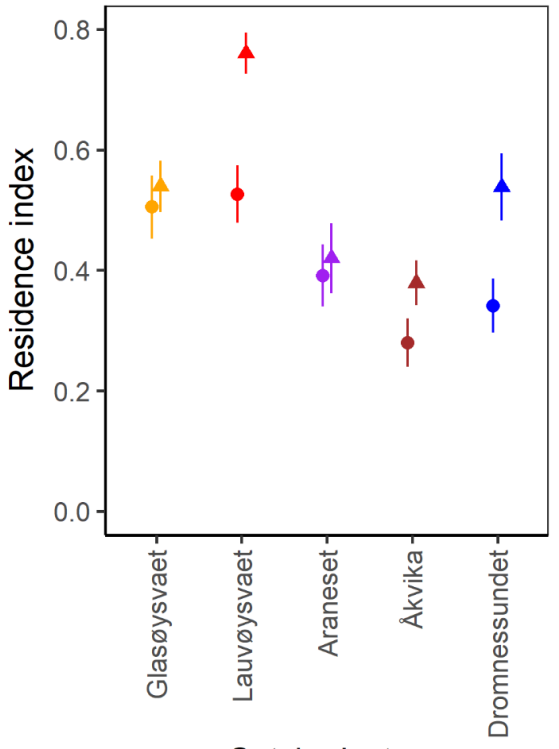

Catch cluster

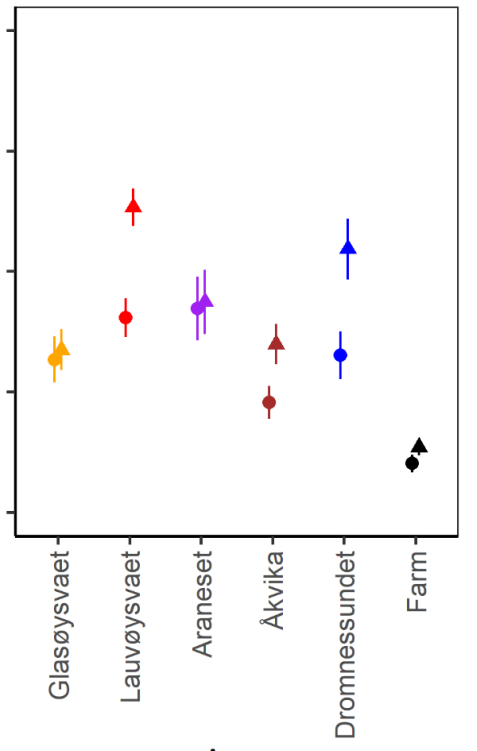

Area
Fig. 3. Residence index during the spawning period for cod using catch clusters as grouping variable (left panel) and using spawning ground as grouping variable (right panel) for females (circles) and males (triangles). Points: mean values; error bars: SE again, males displayed significantly longer maximum residencies than females (Table 4, Fig. 5). At all spawning grounds, fish displayed significantly longer residencies than at the farms (Tukey's post hoc, all $\mathrm{p}<0.01$; Table 4, Fig. 5), but there were also differences between spawning grounds. Lauvøysvaet cod displayed longer maximum residence times than cod at all the other spawning grounds, and Araneset and Dromnessundet cod had longer maximum residencies than Åkvika cod (Table 4, Fig. 5). Cod at Araneset also had longer maximum residencies than cod at Glasøysvaet (Table 4, Fig. 5). Across the different spawning grounds and years, there were 361 occasions where cod had spent at least 1 wk without leaving the area (Glasøysvaet, $\mathrm{n}=54$; Lauvøysvaet, $\mathrm{n}=159$; Araneset, $\mathrm{n}=46$; Åkvika, $\mathrm{n}=46$; Dromnessundet, $\mathrm{n}=56$ ). The maximum recorded residency was $89.1 \mathrm{~d}$, and there were 158 recorded residencies that lasted more than 1 mo (Glasøysvaet, $\mathrm{n}=19$; Lauvøysvaet, $\mathrm{n}=79$; Araneset, $\mathrm{n}=21$; Åkvika, n = 15; Dromnessundet, $\mathrm{n}=24$ ). In contrast, the longest residence time recorded at a farm was $47.6 \mathrm{~d}$, there were only 3 occasions where residencies lasted more than 1 mo and only 19 occasions where cod had spent more than $1 \mathrm{wk}$ at a farm during the spawning period. 


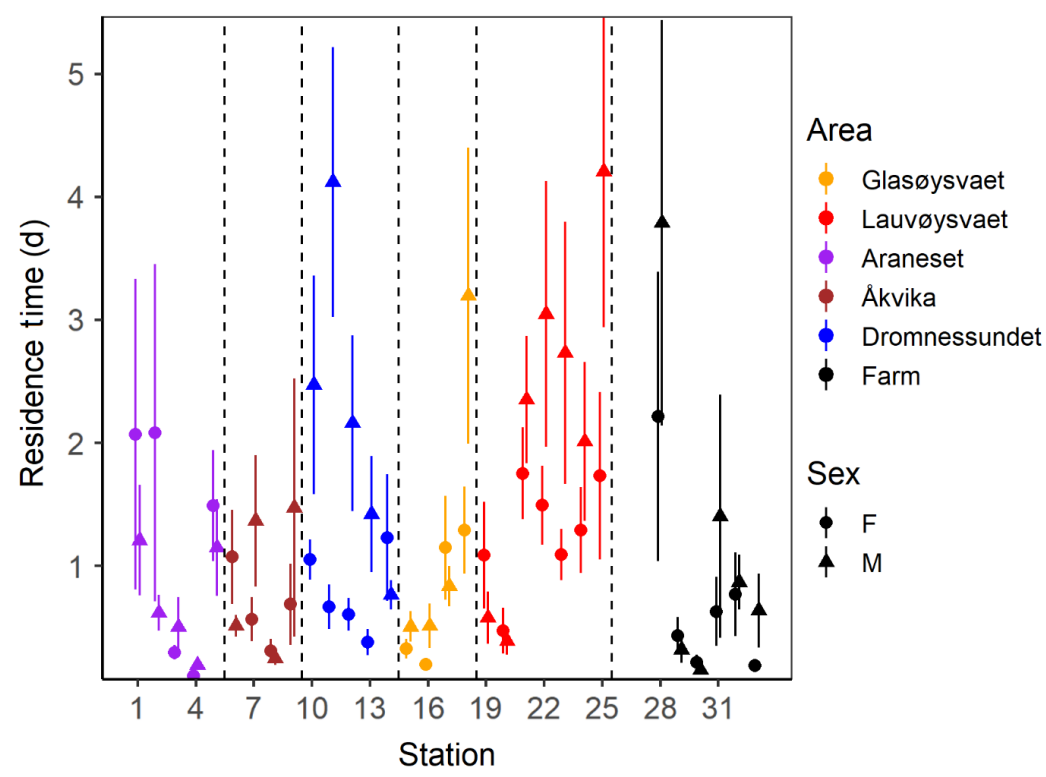

Fig. 4. Residence time during the spawning period for cod at the different stations in the grid. Dotted lines separate different spawning grounds and/or farm stations. Values are shown for both females (circles) and males (triangles) at each station. For each individual fish, the mean residence time at each station was first calculated separately. These values were then used to calculate the mean across all fish present at the station, i.e. the mean of these mean values. Error bars: SE

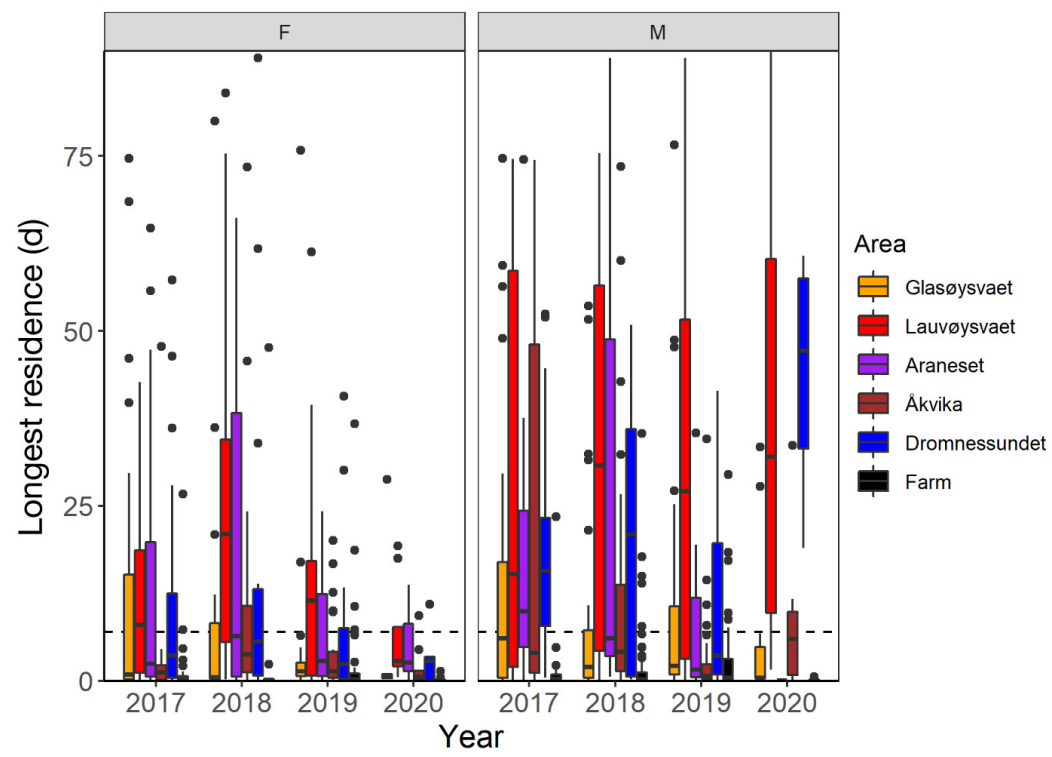

Fig. 5. Longest residence times of individual cod during the putative spawning period at each of the different spawning grounds and at the farms during the study years. Dotted line indicates a residence of $7 \mathrm{~d}$

\subsection{Origin of fish at the different spawning grounds}

There was some connectivity between all spawning grounds, with the only exception being that fish from the Glasøysvaet catch cluster were not detected at the Araneset spawning ground (Fig. 6). There was a significantly higher proportion of mi- grant spawners detected at the Lauvøysvaet spawning ground than at Araneset and Åkvika and more migrant spawners detected at Glasøysvaet than Araneset (Fig. 6, Table 5). The main influx of migrant spawners in Lauvøysvaet was from the adjacent Glasøysvaet spawning ground and vice versa (Fig. 6). When fish from Glasøysvaet or Lauvøysvaet were omitted from the analyses, there was no difference in migrant proportion between any of the grounds.

\section{DISCUSSION}

Using acoustic telemetry, we investigated space utilization of 481 mature and sexed Atlantic cod Gadus morhua caught and released at 5 different spawning grounds. Acoustic receivers were positioned in clusters on these spawning grounds as well as on 6 salmon farms at varying distances from the grounds. Individual cod residency was generally higher at the spawning grounds close to farms but low at the farms themselves, and there was little indication that the tagged cod spawned at the farm localities. In contrast, pronounced spawning activity occurred at the spawning grounds. The finding that spawning grounds close to salmon farms showed the longest residences could, in theory, be related to the nearby farming activity, but further research is needed to establish if this is the case.

\subsection{Attraction of cod to salmon farms}

There are numerous conflicting studies on the residence of cod underneath salmon farms. Some studies suggest that cod are attracted to farms, principally by the opportunity to feed on farm waste, either directly or indirectly by preying on the fish assemblages underneath the farms (Dempster et al. 2009, 2010, 2011, Uglem et al. 2014), while other studies suggest that cod may use olfactory cues to avoid salmon farms (Sæther et al. 2007, Bjørn et al. 2009). 
Table 4. Explanatory variables included in final models of cod residence time (Res Time). Given predictors are the effect of the categorical variables area and sex. Estimates is the parameter estimate of the predictor, CI is the $95 \%$ confidence interval and $\mathrm{p}$ is the $\mathrm{p}$-value. Significance (bold) was assigned at $p<0.05$. The treatment contrast of $R$ was used with the intercept representing the value for females at Glasøysvaet and the value for the other areas and sex showing how they compare to this reference value. Square brackets indicate a categorical variable. The letters show the results of Tukey post hoc tests for the different areas, with different letters indicating significant differences.

Only fixed effects are shown

\begin{tabular}{|c|c|c|c|}
\hline \multirow[b]{2}{*}{ Predictors } & \multicolumn{3}{|c|}{ - Longest residence (days) } \\
\hline & Estimates & $\mathrm{CI}$ & $\mathrm{p}$ \\
\hline Intercept ${ }^{\mathrm{ad}}$ & 6.54 & 3.75 to 9.33 & $<0.001$ \\
\hline 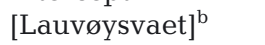 & 14.33 & 10.93 to 17.74 & $<0.001$ \\
\hline [Araneset] ${ }^{\mathrm{c}}$ & 6.34 & 2.11 to 10.58 & 0.003 \\
\hline [Åkvika] ${ }^{\mathrm{d}}$ & -1.89 & -5.50 to 1.73 & 0.306 \\
\hline [Dromnessundet] $^{\mathrm{ac}}$ & 4.01 & -0.00 to 8.02 & 0.050 \\
\hline$[\text { Farm }]^{\mathrm{e}}$ & -7.81 & -11.20 to -4.43 & $<0.001$ \\
\hline Sex [Male] & 6.03 & 3.92 to 8.14 & $<0.001$ \\
\hline Observations & 1110 & & \\
\hline $\mathrm{R}^{2} / \mathrm{R}^{2}$ adjusted & $0.182 / 0.177$ & & \\
\hline
\end{tabular}

We found that cod were more likely to be found on the spawning grounds than at the salmon farms (Fig. 2). This is not unexpected, as cod were caught and released at the spawning grounds and were thus generally closer to spawning ground stations than farm stations when released. However, fish were also less likely to be detected at a farm than a spawning ground station when accounting for distance from release point (Table 3). The tagged cod were thus not aggregating at the farm stations. In apparent contrast, Uglem et al. (2008) caught and released mature cod around a cod farm and observed that a large percentage (50-83\% in their batch $1 ; 40-80 \%$ in their batch 2) of the tagged fish was detected at the farm weekly during their $12 \mathrm{wk}$ experimental period. Some of their tagged fish also visited local spawning grounds, although it is unclear if the latter fish also exhibited prolonged presence at the farms. A possible explanation for these contrasting results is that in the present study we caught, tagged and released fish at the spawning grounds and not at the farms.

\subsection{Residence index and residence times at the different spawning grounds and farms}

Residence index is a common measure of habitat use in acoustic telemetry studies (Zhang et al. 2015, Bordeleau et al. 2018, Lopez-Garro et al. 2020) and can also be used to examine spawning dynamics. Here, we used residence index to assess if proximity to salmon aquaculture farms impacted spawning dynamics on nearby grounds. Cod could, in theory, leave spawning grounds in the vicinity of salmon farms due to either (1) moving to the farms or (2) abandoning these spawning grounds altogether. Regarding point (2), farming practices have been shown to substantially alter surrounding habitats (Kutti et al. 2007a,b, 2008, Valdemarsen et al. 2012, Bannister et al. 2016), possibly rendering nearby spawning grounds less attractive for breeding fish. For both points (1) and (2), the residence index at the spawning grounds would be expected to decrease, whereas (1) would also manifest itself as fish with long residences at the farms. As outlined in the previous paragraph, the tagged cod did not aggregate in large numbers at the farms, and the residence index of fish detected there was shorter than for all spawning grounds (Fig. 4). However, cod were not avoiding the spawning grounds near the farms (i.e. Glasøysvaet and Lauvøysvaet); if anything, the opposite was observed. This was especially true if considering catch cluster as the grouping unit (Fig. 4). If the spawning grounds were used as the grouping unit, this result was not as clear, but cod using the Lauvøysvaet ground still exhibited the numerically longest residences (although only significantly different from Glasøysvaet and Araneset). In theory,

Table 5. Results of the generalized linear model showing differences between spawning grounds in the likelihood of detected cod being migrants, i.e. fish that were not released on the spawning ground in question. Square brackets indicate a categorical variable. The treatment contrast of $\mathrm{R}$ was used with the intercept representing the value for Glasøysvaet and the value for the other spawning grounds showing how they compare to this reference value. The letters show the results of Tukey post hoc tests, with different letters indicating significant differences $(p<0.05)$ between spawning grounds; significant $p$-values are shown in bold

\begin{tabular}{|c|c|c|c|c|}
\hline \multirow[t]{2}{*}{ Predictors } & \multirow[b]{2}{*}{ Log-odds } & \multicolumn{2}{|c|}{ Migrant } & \multirow[b]{2}{*}{$\mathrm{p}$} \\
\hline & & SE & Statistic & \\
\hline Intercept $^{\mathrm{ab}}$ & -0.54 & 0.17 & -3.30 & 0.001 \\
\hline [Lauvøysvaet] $^{\mathrm{b}}$ & 0.29 & 0.22 & 1.31 & 0.189 \\
\hline [Araneset] $^{\mathrm{C}}$ & -1.20 & 0.33 & -3.59 & $<0.001$ \\
\hline [Åkvika] ${ }^{\mathrm{a}}$ & -0.52 & 0.25 & -2.11 & 0.035 \\
\hline [Dromnessundet] $^{\mathrm{abc}}$ & -0.37 & 0.27 & -1.36 & 0.175 \\
\hline Observations & 699 & & & \\
\hline $\mathrm{R}^{2}$ Tjur & 0.042 & & & \\
\hline
\end{tabular}




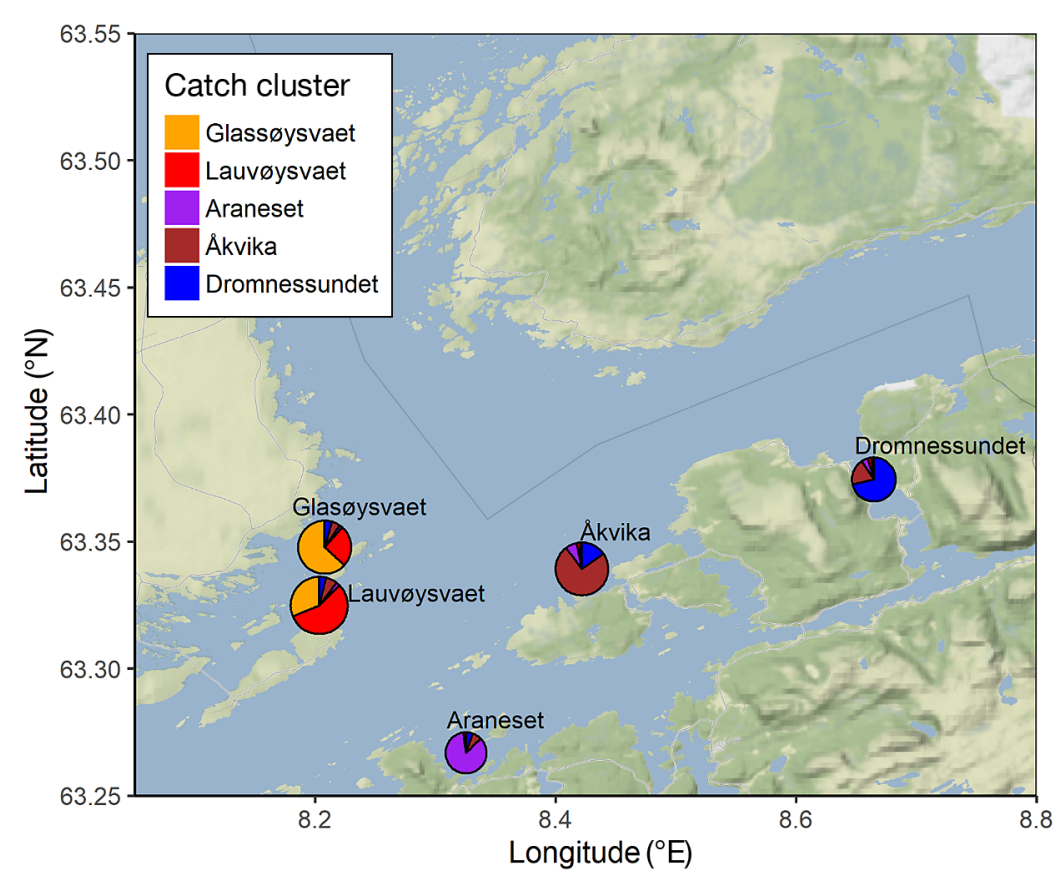

Fig. 6. Origin of cod detected at the 5 different spawning grounds. Size of pie charts are scaled to the number of fish detected

hypothesis of cod mating (Nordeide \& Folstad 2000, Windle \& Rose 2007), whereby male cod form a more stationary and resident shoal with females being more mobile and having larger home ranges during spawning (Meager et al. 2010). The residence index and length of stay reported here, i.e. on average $26 \mathrm{~d}$, is in the upper range of what has previously been reported for telemetry studies on spawning cod (Robichaud \& Rose 2003, Meager et al. 2009, Dean et al. 2014).

Individual residence times or measures of stationarity indicated no overall differences between the spawning ground stations and farm stations during the spawning period, although there was considerable variability between the different stations within areas (Fig. 5). This does not mean that behavioural differences do not exist; indeed, that is likely to be the case. It is more likely that these differences

this behaviour could be linked to the farming activities. Cod could be attracted to the salmon farms (e.g. Uglem et al. 2008, 2014, Dempster et al. 2009) and, although not spawning underneath the farms, they become more prone to using the nearby spawning grounds. In short, spawning grounds usage may have changed when salmon farming started. Given that we have no data on the situation prior to the advent of salmon aquaculture (there are currently more than 30 operational salmon farms in the larger regional study area), we cannot assess whether the spawning dynamics of the different spawning grounds have changed qualitatively from that of the pre-farm situation. Such effects could theoretically be pinpointed through the use some variant of a before-after, control-impact (BACI) design to determine how the system might change after an environmental perturbation (Hogg \& Williams 1996, Tuck et al. 1998, Stewart-Oaten \& Bence 2001, Carstensen et al. 2006).

Cod have a complex, lek-like mating system (Brawn 1961, Hutchings et al. 1999, Nordeide \& Folstad 2000, Meager et al. 2009, 2010, Skjæraasen et al. 2010), commonly involving distinct sex-dependent spatial and temporal dynamics (Meager et al. 2010, Skjæraasen et al. 2011, Dean et al. 2014, Zemeckis et al. 2014). The consistently longer residence indexes and residence times of males compared to females at all spawning grounds sheds important new light on the cod mating system. It tentatively agrees with the lek- will not manifest themselves in residence times calculated from presence/absence data as done here. The spawning ground stations showing the longest residence times may be located close to or at spawning hotspots within the grounds (Fig. 4).

Considering the spawning grounds as one unit and comparing the longest uninterrupted residence time between the spawning grounds and the salmon farms gave contrasting results (Fig. 5). A strength of the present study is that we ascertained the spawning status of fish by ultrasound, biopsies and checking if males were running ripe. Cod are batch spawners, with females releasing numerous batches at semi-regular intervals during the spawning period (Kjesbu 1989, Kjesbu et al. 1996). The batch intervals are temperature-dependent and, at $3-6^{\circ} \mathrm{C}$ (the temperature in the study area during the spawning period; van der Meeren 2019), females are expected to release a batch every 3-4 d. The length of the spawning period for individual fish will vary depending on size and condition (Kjesbu 1989, Kjesbu et al. 1996), but it is likely in the order of $2-4 \mathrm{wk}$ for our tagged fish. Hence, it is unlikely that individual fish would actively be spawning for the total duration of what we have defined as the (group) spawning period, and thus a shorter presence during this period does not conclusively demonstrate spawning. On the other hand, as the release of a batch of eggs itself will only take minutes or even less, spawning could still 
take place during very short residences. Even so, the many fish that had spent very long uninterrupted periods (weeks and months) at the different grounds indicates spawning activity, and, as stated previously, the number of days cod spent on the grounds (i.e. the residence index) was generally longer than previously reported for spawning cod (Robichaud \& Rose 2003, Meager et al. 2009). In contrast, with some exceptions, the longest uninterrupted residencies for individual cod at the salmon farms were short ( $<1$ d). This indicates that for our study fish, pronounced spawning activity was not taking place underneath the farms.

The usage of local spawning grounds may wax and wane over the years (Gonzalez-Irusta \& Wright 2016). Our focal grounds were chosen and delineated based on existing information from fishermen collated by the Norwegian Fisheries Directorate. The present study shows that all focal grounds are currently actively being used by spawning cod. However, ground-wise differences also existed. We do not have data allowing the ground-wise estimation of cod abundance, but qualitatively, the Lauvøysvaet ground appears to be utilised more than the other grounds.

\subsection{Origin of fish at the different spawning grounds}

There was some connectivity between all the different spawning grounds. Most importantly, cod moved between the adjacent Lauvøysvaet and Glasøysvaet spawning grounds, although fish from these grounds also were observed at the 3 other spawning grounds and vice versa. Broadly speaking, most movements were between the spawning grounds at the same side of the fjord-system, i.e. between Lauvøysvaet and Glasøysvaet, and between Aranest, Åkvika and Dromnessundet. Movement between Lauvøysvaet and Glasøysvaet aside, there appeared to be little difference among spawning grounds in their capacity to attract fish that were caught, tagged and released at the other grounds.

\subsection{Caveats}

There are 3 main caveats that need to be acknowledged in the present study. Firstly, cod were caught and released at the spawning grounds. As a group, they then did not end up underneath the farms or appear to spawn there. However, cod are undoubtedly observed underneath salmon farms (Dempster et al. 2009, 2011, Uglem et al. 2014), as also found here. Conversely, if we had actively tagged and release fish underneath the farms, this might have yielded different insights. Indeed, 19 cod spent $>1 \mathrm{wk}$ at the farm stations, possibly engaging in spawning activity with untagged cod underneath the farms. Secondly, only one hydrophone was deployed at each farm. It is possible that features associated with the farms (e.g. the cages, lice skirts, biomass of cultured fish, etc.) reduced the likelihood of detection around the farms somewhat compared to the spawning ground stations. We therefore advocate further studies on the effect of salmon farming on cod reproductive dynamics to evaluate the generality of our findings. Thirdly, we assessed present-day spawning dynamics and spawning ground usage and cannot assess if such dynamics changed upon farm arrival. Despite these caveats, our analysis clearly indicates that the presence of salmon farms has limited effects on the spatiotemporal spawning dynamics of cod presently utilising nearby spawning grounds. The farms are not attracting large numbers of spawners from the grounds, nor are they causing cod to leave the grounds altogether.

Acknowledgements. The present study was financed by the ICOD project (14837-01); a collaborative effort by the Norwegian Fisheries Directorate, MOWI and FHF-Norwegian Seafood Research Fund (project no. 901230). We especially thank Dagfinn Lien for his invaluable help and service during sampling, data download and grid maintenance, Erling Kanestrøm for his help and support in catching fish for the tagging and Odd Gunnar Sørøy for his help with logistics and equipment at MOWI. Knut Staven (MOWI) and Lars Hopmark (Nordmøre Fiskarlag) helped with the overall organization of the study. Numerous employees at MOWI and Salmar farms also provided support when necessary for practical tasks associated with data downloading. Their cooperation is greatly appreciated. All animal sampling and tagging was approved by the Norwegian Authority for Animal Welfare (FOTS ID 8579 and 16616).

\section{LITERATURE CITED}

Ames EP (2004) Atlantic cod stock structure in the Gulf of Maine. Fisheries (Bethesda, Md) 29:10-28

* Bannister RJ, Johnsen IA, Hansen PK, Kutti T, Asplin L (2016) Near- and far-field dispersal modelling of organic waste from Atlantic salmon aquaculture in fjord systems. ICES J Mar Sci 73:2408-2419

Barrett LT, Swearer SE, Harboe T, Karlsen O, Meier S, Dempster T (2018) Limited evidence for differential reproductive fitness of wild Atlantic cod in areas of high and low salmon farming density. Aquacult Environ Interact 10:369-383

Barth JMI, Berg PR, Jonsson PR, Bonanomi S and others (2017) Genome architecture enables local adaptation of Atlantic cod despite high connectivity. Mol Ecol 26: 4452-4466 
Barton K (2020) MuMIn: multi-model inference. R package version 14317. https://cran.r-project.org/web/packages/ MuMIn/index.html

Berg PR, Star B, Pampoulie C, Sodeland M and others (2016) Three chromosomal rearrangements promote genomic divergence between migratory and stationary ecotypes of Atlantic cod. Sci Rep 6:23246

Bjørn PA, Uglem I, Kerwath S, Sæther BS, Nilsen R (2009) Spatiotemporal distribution of Atlantic cod (Gadus morhua L.) with intact and blocked olfactory sense during the spawning season in a Norwegian fjord with intensive salmon farming. Aquaculture 286:36-44

Bordeleau X, Hatcher BG, Denny S, Fast MD, Whoriskey FG, Patterson DA, Crossin GT (2018) Consequences of captive breeding: fitness implications for wild-origin, hatchery-spawned Atlantic salmon kelts upon their return to the wild. Biol Conserv 225:144-153

Brawn VM (1961) Reproductive behaviour of the cod (Gadus callarias L.). Behaviour 18:177-198

Brooks KM, Stierns AR, Mahnken CVW, Blackburn DB (2003) Chemical and biological remediation of the benthos near Atlantic salmon farms. Aquaculture 219:355-377

Buschmann AH, Riquelme VA, Hernandez-Gonzalez MC, Varela D and others (2006) A review of the impacts of salmonid farming on marine coastal ecosystems in the southeast Pacific. ICES J Mar Sci 63:1338-1345

* Campbell HA, Watts ME, Dwyer RG, Franklin CE (2012) VTrack: software for analysing and visualising animal movement from acoustic telemetry detections. Mar Freshw Res 63:815-820

Carstensen J, Henriksen OD, Teilmann J (2006) Impacts of offshore wind farm construction on harbour porpoises: acoustic monitoring of echolocation activity using porpoise detectors (T-PODs). Mar Ecol Prog Ser 321:295-308

* Dahle G, Quintela M, Johansen T, Westgaard JI and others (2018) Analysis of coastal cod (Gadus morhua L.) sampled on spawning sites reveals a genetic gradient throughout Norway's coastline. BMC Genet 19:42

Dean MJ, Hoffman WS, Zemeckis DR, Armstrong MP (2014) Fine-scale diel and gender-based patterns in behaviour of Atlantic cod (Gadus morhua) on a spawning ground in the Western Gulf of Maine. ICES J Mar Sci 71:1474-1489

Dempster T, Sanchez-Jerez P, Bayle-Sempere JT, GimenezCasalduero F, Valle C (2002) Attraction of wild fish to sea-cage fish farms in the south-western Mediterranean Sea: spatial and short-term temporal variability. Mar Ecol Prog Ser 242:237-252

* Dempster T, Uglem I, Sanchez-Jerez P, Fernandez-Jover D, Bayle-Sempere J, Nilsen R, Bjorn PA (2009) Coastal salmon farms attract large and persistent aggregations of wild fish: an ecosystem effect. Mar Ecol Prog Ser 385: $1-14$

Dempster T, Sanchez-Jerez P, Uglem I, Bjorn PA (2010) Species-specific patterns of aggregation of wild fish around fish farms. Estuar Coast Shelf Sci 86:271-275

* Dempster T, Sanchez-Jerez P, Fernandez-Jover D, BayleSempere J, Nilsen R, Bjorn PA, Uglem I (2011) Proxy measures of fitness suggest coastal fish farms can act as population sources and not ecological traps for wild gadoid fish. PLOS ONE 6:e15646

* Edwards P (2015) Aquaculture environment interactions: past, present and likely future trends. Aquaculture 447: 2-14

Espeland SH, Olsen EM, Knutsen H, Gjosaeter J, Danielssen D, Stensethl NC (2008) New perspectives on fish move- ment: kernel and GAM smoothers applied to a century of tagging data on coastal Atlantic cod. Mar Ecol Prog Ser 372:231-241

*Gonzalez-Irusta JM, Wright PJ (2016) Spawning grounds of Atlantic cod (Gadus morhua) in the North Sea. ICES J Mar Sci 73:304-315

* Hogg ID, Williams DD (1996) Response of stream invertebrates to a global-warming thermal regime: an ecosystem-level manipulation. Ecology 77:395-407

* Humborstad OB, Ferter K, Kryvi H, Fjelldal PG (2017) Exophthalmia in wild-caught cod (Gadus morhua L.): development of a secondary barotrauma effect in captivity. J Fish Dis 40:41-49

Hurvich CM, Tsai CL (1989) Regression and time series model selection in small samples. Biometrika 76:297-307

*Hutchings JA, Myers RA, Lilly GR (1993) Geographic variation in the spawning of Atlantic cod, Gadus morhua, in the northwest Atlantic. Can J Fish Aquat Sci 50: 2457-2467

* Hutchings JA, Bishop TD, McGregor-Shaw CR (1999) Spawning behaviour of Atlantic cod, Gadus morhua: evidence of mate competition and mate choice in a broadcast spawner. Can J Fish Aquat Sci 56:97-104

ICES (2020) Arctic Fisheries Working Group (AFWG) 2020 report. ICES Scientific Reports 2:52. http://doi.org/10. 17895/ices.pub.6050

* Johansen T, Besnier F, Quintela M, Jorde PE and others (2020) Genomic analysis reveals neutral and adaptive patterns that challenge the current management regime for East Atlantic cod Gadus morhua L. Evol Appl 13: 2673-2688

Kahle D, Wickham H (2013) ggmap: spatial visualization with ggplot2. R J 5:144-161

Karlsen Ø, Holm JC (1994) Ultrasonography, a noninvasive method for sex determination in cod (Gadus morhua). J Fish Biol 44:965-971

Keeley NB, Macleod CK, Taylor D, Forrest R (2017) Comparison of three potential methods for accelerating seabed recovery beneath salmon farms. Aquaculture 479: 652-666

Keeley N, Valdemarsen T, Woodcock S, Holmer M, Husa V, Bannister R (2019) Resilience of dynamic coastal benthic ecosystems in response to large-scale finfish farming. Aquacult Environ Interact 11:161-179

Kjesbu OS (1989) The spawning activity of cod, Gadus morhua L. J Fish Biol 34:195-206

KKjesbu OS, Solemdal P, Bratland P, Fonn M (1996) Variation in annual egg production in individual captive Atlantic cod (Gadus morhua). Can J Fish Aquat Sci 53:610-620

*Krkosek M, Ford JS, Morton A, Lele S, Myers RA, Lewis MA (2007) Declining wild salmon populations in relation to parasites from farm salmon. Science 318:1772-1775

Kutti T, Ervik A, Hansen PK (2007a) Effects of organic effluents from a salmon farm on a fjord system. I. Vertical export and dispersal processes. Aquaculture 262: $367-381$

Kutti T, Hansen PK, Ervik A, Hoisaeter T, Johannessen P (2007b) Effects of organic effluents from a salmon farm on a fjord system. II. Temporal and spatial patterns in infauna community composition. Aquaculture 262: 355-366

Kutti T, Ervik A, Hoisaeter T (2008) Effects of organic effluents from a salmon farm on a fjord system. III. Linking deposition rates of organic matter and benthic productivity. Aquaculture 282:47-53 
Lopez-Garro A, Zanella I, Golfin-Duarte G, Perez-Montero M (2020) Residency of the whitetip reef shark (Triaenodon obelus) in Chatham and Wafer Bays, Isla del Coco National Park, Costa Rica. Rev Biol Trop 68 (Suppl 1): 330-339 (in Spanish with English Abstract)

Meager JJ, Skjæraasen JE, Ferno A, Karlsen O, Lokkeborg S, Michalsen K, Utskot SO (2009) Vertical dynamics and reproductive behaviour of farmed and wild Atlantic cod Gadus morhua. Mar Ecol Prog Ser 389:233-243

Meager JJ, Skjæraasen JE, Fernö A, Løkkeborg S (2010) Reproductive interactions between fugitive farmed and wild cod (Gadus morhua) in the field. Can J Fish Aquat Sci 67:1221-1231

Moland E, Olsen EM, Knutsen H, Garrigou P and others (2013) Lobster and cod benefit from small-scale northern marine protected areas: inference from an empirical before-after control-impact study. Proc R Soc B 280: 20122679

Nordeide JT, Folstad I (2000) Is cod lekking or a promiscuous group spawner? Fish Fish 1:90-93

Nordeide JT, Johansen SD, Jorgensen TE, Karlsen BO, Moum T (2011) Population connectivity among migratory and stationary cod Gadus morhua in the Northeast Atlantic-a review of 80 years of study. Mar Ecol Prog Ser 435:269-283

Ottera H, Skilbrei OT (2014) Possible influence of salmon farming on long-term resident behaviour of wild saithe (Pollachius virens L.). ICES J Mar Sci 71:2484-2493

R Core Team (2020) R: a language and environment for statistical computing. R Foundation for Statistical Computing, Vienna. www.r-project.org

Robichaud D, Rose GA (2001) Multiyear homing of Atlantic cod to a spawning ground. Can J Fish Aquat Sci 58: 2325-2329

Robichaud D, Rose GA (2003) Sex differences in cod residency on a spawning ground. Fish Res 60:33-43

* Sæther BS, Bjørn PA, Dale T (2007) Behavioural responses in wild cod (Gadus morhua L.) exposed to fish holding water. Aquaculture 262:260-267

Skjæraasen JE, Meager JJ, Karlsen Ø, Mayer I, Dahle G, Rudolfsen G, Fernö A (2010) Mating competition between farmed and wild cod Gadus morhua. Mar Ecol Prog Ser 412:247-258

Skjæraasen JE, Meager JJ, Karlsen Ø, Hutchings JA, Fernö A (2011) Extreme spawning-site fidelity in Atlantic cod. ICES J Mar Sci 68:1472-1477

Stewart-Oaten A, Bence JR (2001) Temporal and spatial variation in environmental impact assessment. Ecol Monogr 71:305-339

* Torrissen O, Jones S, Asche F, Guttormsen A and others (2013) Salmon lice - impact on wild salmonids and salmon aquaculture. J Fish Dis 36:171-194

Tuck ID, Hall SJ, Robertson MR, Armstrong E, Basford DJ (1998) Effects of physical trawling disturbance in a previ-

Editorial responsibility: Pablo Arechavala-Lopez,

Esporles, Illes Balears, Spain

Reviewed by: K. Toledo-Guedes, A. Ozgul and

1 anonymous reviewer ously unfished sheltered Scottish sea loch. Mar Ecol Prog Ser 162:227-242

Uglem I, Bjorn PA, Dale T, Kerwath S and others (2008) Movements and spatiotemporal distribution of escaped farmed and local wild Atlantic cod (Gadus morhua L.). Aquacult Res 39:158-170

* Uglem I, Dempster T, Bjørn PA, Sanchez-Jerez P, Økland F (2009) High connectivity of salmon farms revealed by aggregation, residence and repeated movements of wild fish among farms. Mar Ecol Prog Ser 384:251-260

Uglem I, Karlsen Ø, Sanchez-Jerez P, Sæther BS (2014) Impacts of wild fishes attracted to open-cage salmonid farms in Norway. Aquacult Environ Interact 6:91-103

Valdemarsen T, Bannister RJ, Hansen PK, Holmer M, Ervik A (2012) Biogeochemical malfunctioning in sediments beneath a deep-water fish farm. Environ Pollut 170: $15-25$

van der Meeren T (2019) Undersøkelser av gyte- og oppvekstområder for torsk i Smøla og Aure kommuner våren og høsten 2018. Rapport fra Havforskningen Nr. 26-2019. Havforskningsinstituttet, Bergen. https://www.hi.no/hi/ nettrapporter/rapport-fra-havforskningen-2019-26

*Villegas-Ríos D, Freitas C, Moland E, Thorbjørnsen SH, Olsen EM (2020) Inferring individual fate from aquatic acoustic telemetry data. Methods Ecol Evol 11: 1186-1198

Wickham H (2016) ggplot2: elegant graphics for data analysis, 2nd edn. Springer, Cham

Wickham H, Averick M, Bryan J, Chang W and others (2019) Welcome to the Tidyverse. J Open Source Softw 4: 1686

Windle MJS, Rose GA (2007) Do cod form spawning leks? Evidence from a Newfoundland spawning ground. Mar Biol 150:671-680

Witthames PR, Thorsen A, Murua H, Saborido-Rey F and others (2009) Advances in methods for determining fecundity: application of the new methods to some marine fishes. Fish Bull 107:148-164

*Wood SN (2011) Fast stable restricted maximum likelihood and marginal likelihood estimation of semiparametric generalized linear models. J R Stat Soc B 73:3-36

* Woodcock SH, Strohmeier T, Strand Ø, Olsen SA, Bannister RJ (2018) Mobile epibenthic fauna consume organic waste from coastal fin-fish aquaculture. Mar Environ Res $137: 16-23$

Kemeckis DR, Hoffman WS, Dean MJ, Armstrong MP, Cadrin SX (2014) Spawning site fidelity by Atlantic cod (Gadus morhua) in the Gulf of Maine: implications for population structure and rebuilding. ICES J Mar Sci 71: 1356-1365

Zhang Y, Xu Q, Alos J, Liu H, Xu Q, Yang H (2015) ShortTerm fidelity, habitat use and vertical movement behavior of the black rockfish Sebastes schlegelii as determined by acoustic telemetry. PLOS ONE 10:e0134381

Submitted: January 12, 2021

Accepted: July 20, 2021

Proofs received from author(s): September 29, 2021 